\title{
Delayed but successful response to noninvasive ventilation in COPD patients with acute hypercapnic respiratory failure
}

This article was published in the following Dove Press journal:

International Journal of COPD

25 May 2017

Number of times this article has been viewed

\author{
Malcolm Lemyze ${ }^{1,2}$ \\ Quentin Bury ${ }^{3}$ \\ Aurélie Guiot ${ }^{4}$ \\ Marie Jonard ${ }^{1,2}$ \\ Usman Mohammad ${ }^{2}$ \\ Nicolas Van Grunderbeeck ${ }^{5}$ \\ Gaelle Gasan' \\ Didier Thevenin ${ }^{2}$ \\ Jihad Mallat ${ }^{2}$ \\ 'Department of Respiratory and \\ Critical Care Medicine, Schaffner \\ Hospital, Lens, ${ }^{2}$ Intensive Care Unit, \\ Arras Hospital, Arras, ${ }^{3}$ Respiratory \\ Intermediate Care Unit, Béthune \\ Beuvry Hospital, Béthune, \\ ${ }^{4}$ Department of Cardiology, Bois \\ Bernard Hospital, Bois Bernard, \\ ${ }^{5}$ Respiratory Step Down Unit, \\ Schaffner Hospital, Lens, France
}

Correspondence: Malcolm Lemyze Department of Respiratory and Critical Care Medicine, Schaffner Hospital, 99 route de la Bassée, 62300 Lens, France Email malcolmlemyze@yahoo.fr
Background: We evaluated a new noninvasive ventilation (NIV) protocol that allows the pursuit of NIV in the case of persistent severe respiratory acidosis despite a first NIV challenge in COPD patients with acute hypercapnic respiratory failure (AHRF).

Patients and methods: A prospective observational multicentric pilot study was conducted in three tertiary hospitals over a 12-month study period. A total of 155 consecutive COPD patients who were admitted for AHRF and treated by NIV were enrolled. Delayed response to NIV was defined as a significant clinical improvement in the first $48 \mathrm{~h}$ following NIV initiation despite a persistent severe respiratory acidosis $(\mathrm{pH}<7.30)$ after the first $2 \mathrm{~h}$ of NIV trial.

Results: NIV failed in only 10 patients $(6.5 \%)$. Delayed responders to NIV ( $n=83,53 \%)$ exhibited similar nutritional status, comorbidities, functional status, frailty score, dyspnea score, and severity score at admission, compared with early responders $(n=62,40 \%)$. Only age (66 vs 70 years in early responders; $P=0.03$ ) and encephalopathy score $(3[2-4]$ vs 3 [2-4] in early responders; $P=0.015$ ) were different among the responders. Inhospital mortality did not differ between responders to NIV ( $n=10,12 \%$ for delayed responders vs $n=10,16 \%$ for early responders, $P=0.49$ ). A second episode of AHRF occurred in 20 responders (14\%), equally distributed among early and delayed responders to NIV $(n=9,14.5 \%$ in early responders vs $\mathrm{n}=11,13 \%$ in delayed responders; $P=0.83)$, with a poor survival rate $(\mathrm{n}=1,5 \%)$.

Conclusion: Most of the COPD patients with AHRF have a successful outcome when NIV is pursued despite a persistent severe respiratory acidosis after the first NIV trial. The outcome of delayed responders is similar to the one of the early responders. On the contrary, the second episode of AHRF during the hospital stay carries a poor prognosis.

Keywords: noninvasive ventilation, acute respiratory failure, COPD, hypercapnia, intubation

\section{Introduction}

Since the first randomized clinical trial targeting COPD patients in the early 1990s, a considerable amount of evidence has strongly supported the use of noninvasive ventilation (NIV) to reduce mortality, intubation rates, and the length of stay in hospital in COPD patients with acute hypercapnic respiratory failure (AHRF). ${ }^{1-4}$ Subsequently, international guidelines rightly recommended NIV as the first-line therapy for patients with AHRF.,4 Several authors have carefully advised an escalation to endotracheal intubation in the case of persistent respiratory acidosis after a first NIV challenge. ${ }^{5-7}$ Others have recently tested extracorporeal $\mathrm{CO}_{2}$ removal membrane after a first NIV trial that had failed to reverse hypercapnic acidosis. ${ }^{89}$ However, on the one hand, overcautious recommendations may lead to abusive endotracheal intubation which can increase the risk of ventilator-associated pneumonia, ventilator-associated muscle 
weakness, difficult weaning from mechanical ventilation, and death. On the other hand, invasive procedures such as extracorporeal life supports may seem unsuitable for frail, debilitated COPD patients with advanced chronic respiratory failure. In the "do-not-intubate" (DNI) patients for whom NIV is the treatment of last resort, the technique had been successfully carried out despite persistent severe respiratory acidosis during the first hours. ${ }^{10}$ Similarly, we have conducted a prospective observational pilot study to evaluate a new NIV protocol that allowed the pursuit of NIV when severe respiratory acidosis $(\mathrm{pH}<7.30)$ persisted after the first $2 \mathrm{~h}$ of NIV trial in all the COPD patients admitted for AHRF.

\section{Patients and methods}

\section{Ethics statement}

This prospective observational study was conducted over a 1-year period at three tertiary hospitals in the north of France. It was approved by the Schaffner Hospital's Ethics Committee (approval number 150601). Signed informed consent was obtained from all the patients or next of kin.

\section{Inclusion/exclusion criteria}

All COPD $^{11}$ patients who were admitted for AHRF and treated by NIV were prospectively included. Clinical criteria defining AHRF included the following: tachypnea $(>24$ breaths per minute), Hoover sign, accessory muscle use, and abdominal paradox. ${ }^{12}$ Blood gas criteria for entry included $\mathrm{pH}<7.35$ and $\mathrm{PaCO}_{2}>45 \mathrm{mmHg}$. ${ }^{2}$ Patients with an absolute contraindication to NIV - respiratory arrest and inability to fit a mask ${ }^{2}$ - or refusing NIV, those in AHRF after extubation, and patients with a tracheostomy were excluded from the study.

\section{Evaluation criteria}

Anthropometric data, medical history of respiratory diseases, and nutritional status at admission were recorded. The severity of respiratory disease was evaluated using medical research council (MRC) dyspnea score. ${ }^{13}$ Preadmission health status was assessed by Knaus index ${ }^{14}$ and comorbidities by Charlson comorbidity score. ${ }^{15}$ Patients' frailty was assessed using the clinical frailty scale (Table S1). ${ }^{16}$ The severity of illness at admission and the risk of death were assessed by the Simplified Acute Physiology Score $\mathrm{II}^{17}$ and the Sequential Organ Failure Assessment score. ${ }^{18}$ Nutritional status was evaluated using the body mass index (BMI) calculated as the weight divided by the square of the body height expressed in $\mathrm{kg} / \mathrm{m}^{2}$, and the serum albumin and prealbumin were measured on blood sampling at admission. ${ }^{19}$ Clinical parameters, arterial blood gases, and ventilator settings were measured at admission, 2 h (H2), 4-6 h (H4-6), 12 h (H12), 24 h (H24), and $48 \mathrm{~h}$ (H48) after the initiation of NIV.

\section{NIV technique}

NIV was started as soon as AHRF was identified in either the emergency room, the intensive care unit (ICU), or the respiratory step-down unit. Briefly, NIV was performed using a dedicated ventilator (BiPAP Vision; Philips Respironics, Murrysville, PA, USA, or its new version the V60; Philips Respironics) with its single branch circuit, its calibrated intentional leak, and an interface strategy as previously described in detail. ${ }^{10}$ Bi-level positive pressure ventilation in spontaneous timed ( $\mathrm{S} / \mathrm{T})$ mode was used, and the settings were let at the discretion of the attending physician. NIV was continuously applied until a significant clinical improvement of the patient ensues. Then, the duration of NIV was gradually reduced.

\section{Criteria defining NIV's success and failure}

"Early responders" exhibited a significant decrease in $\mathrm{PaCO}_{2}$ of $\geq 15 \%$ (compared with the initial $\mathrm{PaCO}_{2}$ value under spontaneous breathing) or increase in $\mathrm{pH}>7.30$ after a $2 \mathrm{~h}$ NIV trial associated with a clinical improvement during the first $48 \mathrm{~h}$ after NIV initiation. ${ }^{20,21}$ The patient was considered clinically improved when NIV reversed the clinical signs of respiratory distress - including tachypnea, accessory muscles use, and paradoxical abdominal motion - and improved hypercapnic encephalopathy according to KellyMatthay scale. $^{22}$

"Delayed responders" exhibited a significant clinical improvement leading to their recovery from AHRF in the first $48 \mathrm{~h}$ despite persistent respiratory acidosis after the first trial of face mask-delivered NIV. Persistent respiratory acidosis referred to the inability to obtain a significant decrease in $\mathrm{PaCO}_{2}$ of $\geq 15 \%$ (compared with the initial $\mathrm{PaCO}_{2}$ value under spontaneous breathing) or increase in $\mathrm{pH}>7.30$ after $2 \mathrm{~h}$ of facial mask-delivered NIV. ${ }^{20}$

"Early NIV failure" ( $<48 \mathrm{~h}$ ) was defined as the need to resort to intubation or palliative care - in the case of DNI order (Supplementary materials) - according to major and minor criteria already used in the literature. ${ }^{1}$ Major criteria included respiratory arrest, respiratory pauses, or bradycardia $(<50 \mathrm{bpm})$ with the loss of consciousness, hypotension with systolic arterial blood pressure below $70 \mathrm{mmHg}$, and refractory hypoxemia with the inability to maintain an $\mathrm{SaO}_{2}>90 \%$ despite high $\mathrm{FiO}_{2}>60 \%$. Minor criteria included tachypnea over 35 bpm or increase in the respiratory rate compared with 
its value at admission, $\mathrm{pH}<7.30$, and decrease compared with its initial value, an increase in the encephalopathy score compared with its initial value (according to Kelly-Matthay scale $^{22}$ ). Early NIV failure was considered when one major criterion was present, or when two minor criteria persisted after $6 \mathrm{~h}$ of NIV. When respiratory rate, encephalopathy score, $\mathrm{PaCO}_{2}$, or $\mathrm{pH}$ did not immediately improve with face maskdelivered NIV, patient's positioning was double checked to ensure a proper sitting position, and the interface could be changed to a total face mask. ${ }^{10}$ If one or more minor criteria appeared after NIV had been resumed, NIV could be tried again. When NIV failed, escalation to endotracheal intubation was proceeded unless the patient had received a DNI order. In that case, palliative care was initiated. According to the protocol of good ethical practice of our hospital, if intubation was deemed inappropriate, the patient could be classified as DNI as previously described (additional definition is given in Supplementary materials). ${ }^{10}$

"Late failure" ( $>48 \mathrm{~h}$ ) was defined as a sudden or gradual deterioration in arterial blood gases $(\mathrm{pH}<7.34$ with an increase in $\mathrm{PaCO}_{2}>15 \%-20 \%$ compared with the previous value) with worsening of dyspnea, after an initial phase of partial recovery, even though NIV was continued at least $6 \mathrm{~h}$ a day. ${ }^{20,21}$

\section{Statistical analysis}

The normality of data distribution was assessed using the Kolmogorov-Smirnov test. When normally distributed, continuous data were compared using Student's $t$-test; otherwise, the Mann-Whitney $U$ test was applied. Analysis of the discrete data was performed by Fisher's exact test. Statistical analyses were performed using SPSS (SPSS for windows release 17.0, SPSS Inc., Chicago, IL, USA). A $P$-value of $<0.05$ was considered statistically significant for single comparisons. All the reported $P$-values were two sided.

\section{Results}

Among the 155 COPD patients with AHRF, early NIV failure occurred in only 10 patients $(6.5 \%)$, while 145 patients $(93.5 \%)$ were initially successfully treated by NIV. Inhospital mortality was $16 \%(n=25)$ considering the overall population, $50 \%(\mathrm{n}=5)$ in the early NIV failure group compared with $14 \%(n=20)$ in the NIV success group $(P=0.01)$. The main patients' characteristics according to the response to NIV are listed in Table 1.

Table 2 compares the main patients' characteristics between early $(n=62)$ and delayed responders $(n=83)$. In both groups, patients exhibited low serum albumin and prealbumin levels, a high MRC dyspnea score, a high Charlson comorbidity score, a poor functional status as demonstrated by a large proportion of patients classified as $\mathrm{C}$ or $\mathrm{D}$ according to the Knaus index, and a high clinical frailty score. In univariate analysis, the only distinctive characteristics of the delayed responders compared with the early responders to NIV were a lower age and a higher encephalopathy score at admission. The outcome of patients with a delayed response to NIV was similar to the one of the early responders. Among those with a $\mathrm{pH}<7.25$ after the first $2 \mathrm{~h}$ of NIV trial $(\mathrm{n}=26), 21$ patients $(80.7 \%)$ survived hospital discharge with this NIV protocol. As shown in Figure 1, in the NIV success group ( $n=145)$, only two patients died from extra-respiratory causes - one from aortic dissection and the other from septic shock - although they had recovered from the first episode of AHRF under NIV. The vast majority of the inhospital deaths among the patients of the NIV success group were caused by "late NIV failure" which corresponded to a second episode of AHRF. All but one patient ( $n=19 / 20)$ who developed a second episode of AHRF while NIV was pursued - late NIV failure - died in hospital.

\section{Discussion}

This study shows that 1) a substantial number of COPD patients with AHRF exhibit a delayed but successful response to NIV when the latter is continued despite a persistent severe respiratory acidosis after the first NIV trial; 2) these delayed responders to NIV experience same outcome as the one of the early responders; and 3) a second episode of AHRF under NIV carries a bad prognosis.

The current study is exclusively focused on type 2 (hypercapnic) or AHRF, which results from a pump dysfunction of the respiratory system. This scenario - acuteon-chronic ventilatory failure - refers to the incapacity of the ventilatory pump to assume the work of breathing, leading to alveolar hypoventilation and hypercapnia. The current population includes particularly frail COPD patients with higher dyspnea score, lower functional status, severe malnutrition, and much more comorbidities than the individuals usually enrolled in the studies about the exacerbation of COPD, even in those including patients with a DNI order. ${ }^{21,23}$ In such a fragile population, NIV provides considerable benefits, especially to prevent the complications associated with invasive mechanical ventilation. ${ }^{1-4}$ Gradually, NIV has been successfully applied in many circumstances of AHRF that were initially considered as contraindications to its use. ${ }^{10,24}$ While the previously published guidelines included severe encephalopathy in 
Table I Patients' characteristics according to the response to NIV

\begin{tabular}{|c|c|c|c|c|}
\hline Characteristics & $\begin{array}{l}\text { Overall population } \\
(n=155)\end{array}$ & $\begin{array}{l}\text { NIV failure } \\
(n=10 ; 6.5 \%)\end{array}$ & $\begin{array}{l}\text { NIV success } \\
(n=145 ; 93.5 \%)\end{array}$ & $P$-value \\
\hline Age (years) & $68 \pm 12$ & $69 \pm 10$ & $68 \pm 12$ & 0.70 \\
\hline Male, n (\%) & 114 (73.6\%) & $8(80 \%)$ & 106 (73\%) & 0.63 \\
\hline $\mathrm{BMI}\left(\mathrm{kg} / \mathrm{m}^{2}\right)$ & $29.5(23.8-38.7)$ & $24.0(18.0-29.1)$ & $31.0(24.0-39.1)$ & 0.03 \\
\hline SOFA score & $4.0(3.0-5.0)$ & $5.5(3.0-6.0)$ & $4.0(3.0-5.0)$ & 0.27 \\
\hline Charlson comorbidity score & $3(2-5)$ & $4(3-5)$ & $3(2-5)$ & 0.37 \\
\hline SAPS 2 & $36 \pm 11$ & $43 \pm 20$ & $35 \pm 10$ & 0.23 \\
\hline MRC dyspnea score & $5(4-5)$ & $5(4-5)$ & $5(4-5)$ & 0.72 \\
\hline DNI order, n (\%) & $96(62 \%)$ & $5(40 \%)$ & $91(63 \%)$ & 0.18 \\
\hline Knaus index C, n (\%) & $51(33 \%)$ & $2(20 \%)$ & $49(34 \%)$ & 0.50 \\
\hline Knaus index D, $\mathrm{n}(\%)$ & 74 (48\%) & $6(60 \%)$ & $68(47 \%)$ & 0.52 \\
\hline Clinical frailty score & $6(5-7)$ & $6(5-7)$ & $6(5-7)$ & 0.58 \\
\hline Heart rate (bpm) & $104 \pm 21$ & $107 \pm 20$ & $103 \pm 21$ & 0.62 \\
\hline Respiratory rate (bpm) & $28 \pm 7$ & $26 \pm 8$ & $28 \pm 7$ & 0.55 \\
\hline Encephalopathy score & $3(2-4)$ & $4(I-5)$ & $3(2-4)$ & 0.24 \\
\hline Systolic blood pressure $(\mathrm{mmHg})$ & $137 \pm 26$ & $119 \pm 24$ & $139 \pm 26$ & 0.03 \\
\hline Albumin $(g / L)$ & $29.7 \pm 5.6$ & $26.3 \pm 5.6$ & $30.0 \pm 5.5$ & 0.08 \\
\hline Prealbumin $(g / L)$ & $0.15 \pm 0.07$ & $0.12 \pm 0.04$ & $0.15 \pm 0.07$ & 0.07 \\
\hline Respiratory depressant drugs, n (\%) & $31(20)$ & $\mathrm{I}(10)$ & $30(21)$ & 0.68 \\
\hline Pneumonia, $\mathrm{n}(\%)$ & $57(37)$ & $5(50)$ & $52(36)$ & 0.50 \\
\hline Congestive heart failure, $\mathrm{n}(\%)$ & $22(14)$ & $\mathrm{I}(10)$ & $21(14.5)$ & 1.00 \\
\hline Idiopathic, n (\%) & $68(44)$ & $3(30)$ & $65(45)$ & 0.51 \\
\hline Sepsis, n (\%) & $3(2)$ & $\mathrm{I}(10)$ & $2(1.4)$ & 0.18 \\
\hline Pulmonary embolism, n (\%) & $3(2)$ & $0(0)$ & $3(2.1)$ & 1.00 \\
\hline Others, n (\%) & $2(1)$ & $0(0)$ & $2(1.4)$ & 1.00 \\
\hline $\mathrm{pH}$ & $7.25(7.19-7.32)$ & $7.20(7.14-7.33)$ & $7.26(7.20-7.32)$ & 0.42 \\
\hline $\mathrm{PaCO}_{2}(\mathrm{mmHg})$ & $76(62-90)$ & $76(62-86)$ & $76(62-90)$ & 0.83 \\
\hline $\mathrm{PaO}_{2} / \mathrm{FiO}_{2}$ & $227 \pm 74$ & $255 \pm 83$ & $226 \pm 74$ & 0.30 \\
\hline $\mathrm{FiO}_{2}(\%)$ & $30(25-45)$ & $30(25-45)$ & $30(25-40)$ & 0.87 \\
\hline $\mathrm{HCO}_{3}^{-}(\mathrm{mmol} / \mathrm{L})$ & $33.2 \pm 6.8$ & $31.7 \pm 5.4$ & $33.3 \pm 7.0$ & 0.40 \\
\hline $\operatorname{EPAP}\left(\mathrm{cmH}_{2} \mathrm{O}\right)$ & $8(6-8)$ & $8(6-8)$ & $8(6-8)$ & 0.92 \\
\hline $\operatorname{IPAP}\left(\mathrm{cmH}_{2} \mathrm{O}\right)$ & $18(16-18)$ & $18(17-20)$ & $18(16-18)$ & 0.32 \\
\hline Inhospital mortality, n (\%) & $25(16 \%)$ & $5(50 \%)$ & $20(14 \%)$ & 0.01 \\
\hline LOS in hospital & $13(8-17)$ & $11.5(1-19)$ & $13(9-17)$ & 0.42 \\
\hline
\end{tabular}

Note: Data presented as mean \pm SD or median (interquartile range, 25-75).

Abbreviations: BMI, body mass index; bpm, beat/breath per minute; DNI, do-not-intubate; EPAP, expiratory positive airway pressure; IPAP, inspiratory positive airway pressure; LOS, length of stay; MRC, Medical Research Council; NIV, noninvasive ventilation; SAPS 2, simplified acute physiologic score 2; SOFA, sequential organ failure assessment score.

their contraindications to NIV, ${ }^{3}$ Díaz et al ${ }^{24}$ demonstrated a significantly greater NIV success rate in a large population of COPD patients in hypercapnic coma compared with those without severely impaired consciousness at admission $(\mathrm{n}=76 / 95,80 \%$ vs $\mathrm{n}=605 / 863,70 \% ; P=0.04)$. The patients who exhibit our "delayed but successful response to NIV" are usually considered at very high risk for intubation. Despite a more severe hypercapnic encephalopathy at admission, these delayed responders to NIV exhibited the same outcome as the one of the early responders without the resort to intubation.

The literature about NIV for AHRF of COPD patients without treatment limitation decision constantly defines NIV failure as the need to resort to intubation and to invasive mechanical ventilation. ${ }^{1-9}$ The primary concern with the studies that have shown that the persistence of low $\mathrm{pH}$ or high $\mathrm{PaCO}_{2}$ at $\mathrm{H} 2$ predicted NIV failure is that these same variables were also used as main criteria to define NIV failure. ${ }^{5,6}$ Thus, it is not surprising that the same variables that are related to outcome status were found to be good predictors of the occurrence of the outcome (outcome classification bias) ${ }^{25}$ In other words, if in the study protocol low $\mathrm{pH}$ and high $\mathrm{PaCO}_{2}$ motivate the resort to intubation, and NIV failure is defined as the need to resort to intubation, then obviously $\mathrm{pH}$ and $\mathrm{PaCO}_{2}$ are expected to be associated with NIV failure. Even in the largest multicentric European study including 1,033 COPD patients, this pitfall was not avoided with 186 patients who were intubated because of "NIV failure" mostly defined by arterial blood gases (ABG) criteria. ${ }^{6}$ Inhospital mortality has reached $49 \%$ in that group. According to this large study, $\mathrm{pH}<7.25$ at $\mathrm{H} 2$ is associated with a risk of intubation exceeding $90 \% .{ }^{6}$ In the current 
Table 2 Comparison of the early responders with the delayed responders to NIV

\begin{tabular}{|c|c|c|c|}
\hline Parameters & $\begin{array}{l}\text { Early responders } \\
(n=62)(\%)\end{array}$ & $\begin{array}{l}\text { Delayed responders } \\
(n=83)(\%)\end{array}$ & $P$-value \\
\hline Age (years) & $70 \pm 11$ & $66 \pm 13$ & 0.03 \\
\hline Male, n (\%) & $47(76)$ & $59(7 \mathrm{I})$ & 0.40 \\
\hline $\mathrm{BMI}\left(\mathrm{kg} / \mathrm{m}^{2}\right)$ & $32.7(23-38)$ & $29.5(24-40)$ & 0.68 \\
\hline SOFA score & $4(3-4)$ & $4(3-5)$ & 0.21 \\
\hline SAPS 2 & $34 \pm 9.6$ & $36 \pm 9.8$ & 0.30 \\
\hline Charlson comorbidity score & $4(3-5)$ & $3(2-4)$ & 0.09 \\
\hline MRC dyspnea score & $5(4-5)$ & $5(4-5)$ & 0.53 \\
\hline DNI order, n (\%) & $43(69)$ & $49(59)$ & 0.20 \\
\hline Knaus index C, $\mathrm{n}(\%)$ & $19(30)$ & $30(36)$ & 0.48 \\
\hline Knaus index D, n (\%) & $34(55)$ & $34(4 I)$ & 0.10 \\
\hline Clinical frailty score & $7(5-7)$ & $6(4-7)$ & 0.12 \\
\hline Heart rate $(\mathrm{bpm})$ & $105 \pm 20$ & $102 \pm 22$ & 0.30 \\
\hline Respiratory rate (bpm) & $29 \pm 6$ & $27 \pm 7$ & 0.15 \\
\hline Encephalopathy score & $3(2-4)$ & $3(2-4)$ & 0.015 \\
\hline Systolic blood pressure $(\mathrm{mmHg})$ & $140 \pm 25$ & $137 \pm 27$ & 0.49 \\
\hline Albumin $(g / L)$ & $29.7 \pm 6$ & $30.1 \pm 5$ & 0.70 \\
\hline Prealbumin $(g / L)$ & $0.16 \pm 0.06$ & $0.14 \pm 0.07$ & 0.31 \\
\hline Respiratory depressant drugs, n (\%) & $9(14.5)$ & $21(25.3)$ & 0.11 \\
\hline \multicolumn{4}{|l|}{ Causes of AHRF, $n(\%)$} \\
\hline Pneumonia & $22(35.5)$ & $30(36)$ & 0.93 \\
\hline Congestive heart failure & $11(17.7)$ & $10(12)$ & 0.33 \\
\hline Idiopathic & $25(40)$ & $40(48)$ & 0.35 \\
\hline Sepsis & $\mathrm{I}(\mathrm{I} .6)$ & $\mathrm{I}(1.2)$ & 0.83 \\
\hline Pulmonary embolism & $2(3.2)$ & $\mathrm{I}(\mathrm{I} .2)$ & 0.58 \\
\hline Other & $\mathrm{I}(1.6)$ & $\mathrm{I}(1.2)$ & 1.00 \\
\hline $\mathrm{pH}$ & $7.27(7.23-7.33)$ & $7.25(7.19-7.33)$ & 0.17 \\
\hline $\mathrm{PaCO}_{2}(\mathrm{mmHg})$ & $73(6 \mid-82)$ & $80(62-91)$ & 0.06 \\
\hline $\mathrm{PaO}_{2} / \mathrm{FiO}_{2}$ & $222 \pm 70$ & $229 \pm 76$ & 0.57 \\
\hline $\mathrm{FiO}_{2}(\%)$ & $30(25-45)$ & $30(25-40)$ & 0.51 \\
\hline $\mathrm{HCO}_{3}^{-}(\mathrm{mmol} / \mathrm{L})$ & $33 \pm 7$ & $33.5 \pm 6$ & 0.73 \\
\hline $\operatorname{EPAP}^{3}\left(\mathrm{cmH}_{2} \mathrm{O}\right)$ & $7.5(6-8)$ & $8(6-8)$ & 0.04 \\
\hline IPAP $\left(\mathrm{cmH}_{2} \mathrm{O}\right)$ & $17(16-18)$ & $18(16-19)$ & 0.24 \\
\hline \multicolumn{4}{|l|}{ Outcome, n (\%) } \\
\hline Late NIV failure & $9(14.5)$ & II (I3.2) & 0.83 \\
\hline Inhospital death & $10(16 \%)$ & $10(12 \%)$ & 0.49 \\
\hline
\end{tabular}

Note: Data presented as mean \pm SD or median (interquartile range, 25-75).

Abbreviations: AHRF, acute hypercapnic respiratory failure; BMI, body mass index; bpm, beat/breath per minute; DNI, do-not-intubate; EPAP, expiratory positive airway pressure; IPAP, inspiratory positive airway pressure; MRC, medical research council; NIV, noninvasive ventilation; SAPS 2, simplified acute physiologic score 2; SOFA, sequential organ failure assessment score.

population of very frail COPD patients, among the delayed responders to NIV, 26 patients (31\%) had a $\mathrm{pH}<7.25$ after the first $2 \mathrm{~h}$ of NIV trial and should have been intubated according to these recommendations. ${ }^{5,6} \mathrm{~A}$ total of 21 of these patients $(81 \%)$ survived hospital discharge with this protocol allowing the pursuit of NIV, while inhospital mortality was drastically lower (19\%) with our protocol than in all the previously published studies about hypercapnic COPD patients at high risk for intubation according to the ABG's criteria. Far from delaying intubation, our "more NIV" strategy might rather prevent complications associated with invasive mechanical ventilation especially in frail patients with chronic respiratory failure prone to difficult weaning from mechanical ventilation.
Among the patients initially improved by NIV during the first $48 \mathrm{~h}, 13.8 \%$ of them exhibited a second episode of AHRF despite NIV was carried on. This late NIV failure scenario was associated with a dreadful prognosis. This result is in agreement with previously published data in obese ${ }^{17}$ and COPD patients. ${ }^{18}$ Our population includes frail malnourished individuals with severe chronic respiratory failure and many comorbidities who became even more weakened after the first episode of AHRF ${ }^{26}$ Acute respiratory failure classically worsens systemic inflammation and malnutrition and causes prolonged confinement to bed and sleep disturbances, all of which precipitate the deterioration of respiratory function. ${ }^{26-28}$ Another explanation lies on the refusal of many frail DNI patients to pursue NIV after 


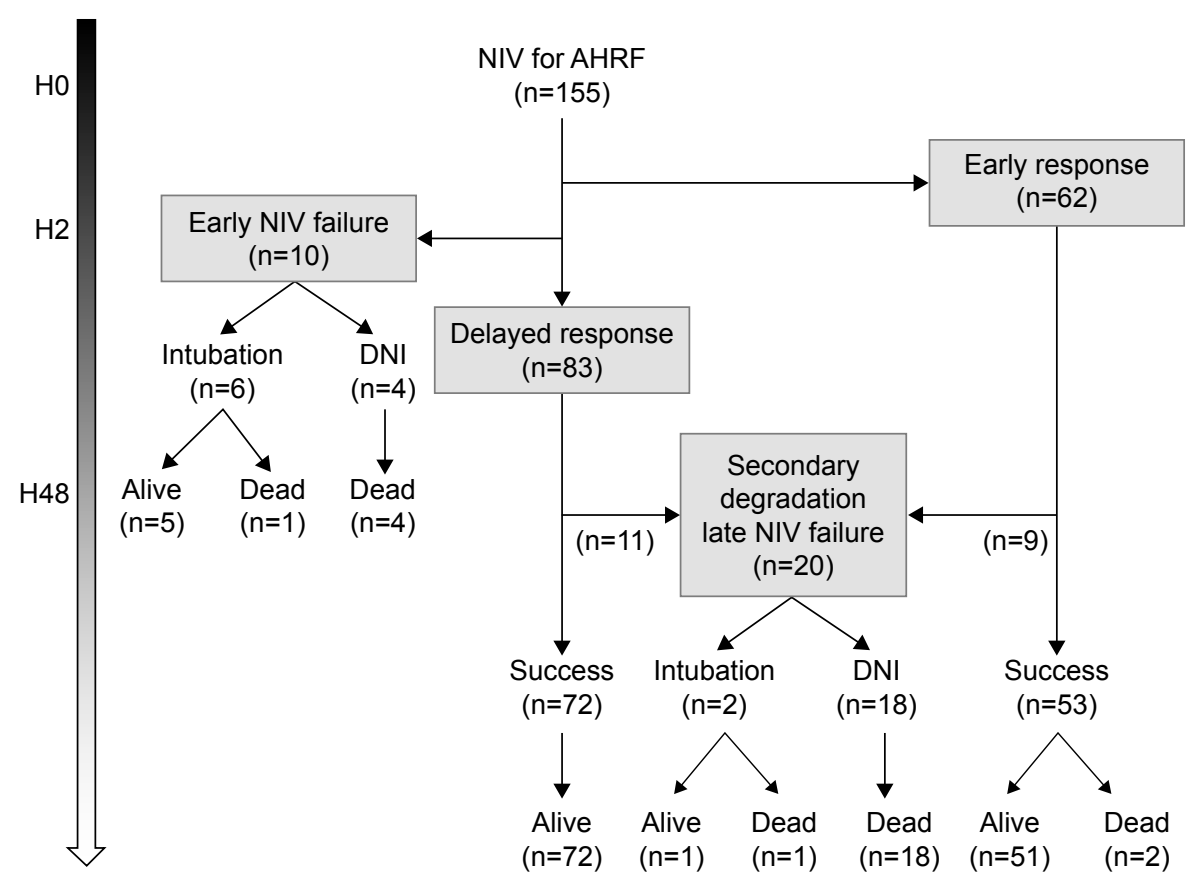

Figure I Flowchart of the distribution of patients according to the response to NIV. Note: $\mathrm{HO}$, at NIV initiation; $\mathrm{H} 2$, after $2 \mathrm{~h}$ of NIV trial; and $\mathrm{H} 48$, after $48 \mathrm{~h}$ of NIV.

Abbreviations: AHRF, acute hypercapnic respiratory failure; DNI, do-not-intubate; NIV, noninvasive ventilation.

several days of hospitalization. Depression and anxiety are common symptoms in hospitalized COPD patients, which are often overlooked in spite of their significant impact on mortality following acute exacerbation of COPD. ${ }^{29}$ It should be stressed that depression can clearly influence the end-of-life decisions of hospitalized COPD patients toward "do-not-resuscitate" or DNI orders. ${ }^{30}$ As hospitalization may exacerbate the symptoms of depression, many of these vulnerable patients can decide to stop a treatment such as NIV they find uncomfortable. From an ethical point of view, NIV has to be considered as a life support modality that cannot be imposed by force, especially in the most debilitated ones with a DNI status. In that case, NIV may be abandoned to respect the patient's wishes in favor of palliative care, thus precipitating inhospital death. The previous explanations help to understand the very high inhospital mortality rate of this subgroup of patients characterized by a second episode of AHRF that occurs despite the pursuit of NIV. ${ }^{21}$

Some limitations have to be acknowledged. Of course, the non-randomized study design can be considered as a true methodological limitation. However, this is the first pilot study that was conducted in the real-life conditions of three different centers according to a strict protocol that allows the pursuit of NIV in the most refractory cases of AHRF. All efforts were made to provide NIV in the same conditions for all the patients wherever they were managed. Thus, NIV was started using the same ventilator, the same circuit and interface, and the same pressure-cycled mode in all the patients. Our findings should be confirmed by large controlled trials but question the current recommended approach based on the early resort to intubation when severe respiratory acidosis persists after the first NIV challenge.

\section{Conclusion}

Most of the COPD patients managed with NIV for AHRF exhibit a persistent severe respiratory acidosis $(\mathrm{pH}<7.3)$ after the first 2 hours of NIV trial. These delayed responders to NIV need some more time to recover from AHRF, but finally they have a similar outcome without the resort to intubation than those who immediately correct their arterial blood gases under NIV. On the opposite, a second episode of acute respiratory failure while NIV is pursued is associated with a poor prognosis.

\section{Disclosure}

The authors report no conflicts of interest in this work.

\section{References}

1. Brochard L, Mancebo J, Wysocki M, et al. Noninvasive ventilation for acute exacerbations of chronic obstructive pulmonary disease. $N$ Engl J Med. 1995;333(13):817-822.

2. Nava S, Hill N. Non-invasive ventilation in acute respiratory failure. Lancet. 2009;374(9685):250-259. 
3. Evans TW. International Consensus Conference in Critical Care Medicine. Noninvasive positive pressure ventilation in acute respiratory failure. Am J Respir Crit Care Med. 2001;163:283-291.

4. Davidson AC, Banham S, Elliott M, et al. British Thoracic Society/ Intensive Care Society Guideline for the ventilatory management of acute hypercapnic respiratory failure in adults. Thorax. 2016;71(suppl2): ii1-ii35.

5. Ambrosino N, Foglio K, Rubini F, Clini E, Nava S, Vitacca M. Noninvasive mechanical ventilation in acute respiratory failure due to chronic obstructive pulmonary disease: correlates for success. Thorax. 1995;50(7):755-757.

6. Confalonieri M, Garuti G, Cattaruzza MS, et al; Italian Noninvasive Positive Pressure Ventilation (NPPV) Study Group. A chart of failure risk for noninvasive ventilation in patients with COPD exacerbation. Eur Respir J. 2005;25(2):348-355.

7. Jolliet P, Ouanes-Besbes L, Abroug F, et al; E.C.H.O.ICU Trial Investigators. A multicenter randomized trial assessing the efficacy of helium/oxygen in severe exacerbations of chronic obstructive pulmonary disease. Am J Respir Crit Care Med. 2017;195(7):871-888.

8. Burki NK, Mani RK, Herth FJ, et al. A novel extracorporeal CO(2) removal system: results of a pilot study of hypercapnic respiratory failure in patients with COPD. Chest. 2013;143(3):678-686.

9. Braune S, Sieweke A, Brettner F, et al. The feasibility and safety of extracorporeal carbon dioxide removal to avoid intubation in patients with COPD unresponsive to noninvasive ventilation for acute hypercapnic respiratory failure (ECLAIR study): multicentre case-control study. Intensive Care Med. 2016;42(9):1437-1444.

10. Lemyze M, Mallat J, Barrailler S, et al. Rescue therapy by switching to total face mask after failure of face mask-delivered noninvasive ventilation in do-not-intubate patients in acute respiratory failure. Crit Care Med. 2013;41(2):481-488.

11. Rabe KF, Hurd S, Anzueto A, et al; Global Initiative for Chronic Obstructive Lung Disease. Global strategy for the diagnosis, management, and prevention of chronic obstructive pulmonary disease: GOLD executive summary. Am J Respir Crit Care Med. 2007;176(6):532-555.

12. Lemyze M, Bart F. Hoover sign. CMAJ. 2011;183(2):E133.

13. Fletcher CM. Standardised questionnaire on respiratory symptoms: a statement prepared and approved by the MRC committee on the aetiology of chronic bronchitis (MRC breathlessness score). BMJ. 1960;2:1665.

14. Knaus WA, Draper EA, Wagner DP, et al. APACHE II: a severity of disease classification. Crit Care Med. 1985;13:818-829.

15. Charlson ME, Pompei P, Ales KL, MacKenzie CR. A new method of classifying prognostic comorbidity in longitudinal studies: development and validation. J Chronic Dis. 1987;40(5):373-383.
16. Rockwood K, Song X, MacKnight C, et al. A global clinical measure of fitness and frailty in elderly people. CMAJ. 2005;173(5):489-495.

17. Le Gall JR, Lemeshow S, Saulnier F. A new Simplified Acute Physiology Score (SAPS II) based on a European/North American multicenter study. JAMA. 1993;270:2957-2963.

18. Ferreira FL, Bota DP, Bross A, Mélot C, Vincent JL. Serial evaluation of the SOFA score to predict outcome in critically ill patients. JAMA. 2001;286(14):1754-1758.

19. Connors AF Jr, Dawson NV, Thomas C, et al. Outcomes following acute exacerbation of severe chronic obstructive lung disease. Am J Respir Crit Care Med. 1996;154(4 pt 1):959-967.

20. Lemyze M, Taufour P, Duhamel A, et al. Determinants of noninvasive ventilation success or failure in morbidly obese patients in acute respiratory failure. PLoS One. 2014;9(5):e97563.

21. Moretti M, Cilione C, Tampieri A, Fracchia C, Marchioni A, Nava S. Incidence and causes of non-invasive mechanical ventilation failure after initial success. Thorax. 2000;55(10):819-825.

22. Kelly BJ, Matthay MA. Prevalence and severity of neurologic dysfunction in critically ill patients. Influence on need for continued mechanical ventilation. Chest. 1993;104(6):1818-1824.

23. Chu CM, Chan VL, Wong IW, Leung WS, Lin AW, Cheung KF. Noninvasive ventilation in patients with acute hypercapnic exacerbation of chronic obstructive pulmonary disease who refused endotracheal intubation. Crit Care Med. 2004;32(2):372-377.

24. Díaz GG, Alcaraz AC, Talavera JC, et al. Noninvasive positive-pressure ventilation to treat hypercapnic coma secondary to respiratory failure. Chest. 2005;127(3):952-960.

25. Delgado-Rodríguez M, Llorca J. Bias. J Epidemiol Community Health. 2004;58(8):635-641.

26. Seemungal TA, Donaldson GC, Bhowmik A, Jeffries DJ, Wedzicha JA. Time course and recovery of exacerbations in patients with chronic obstructive pulmonary disease. Am J Respir Crit Care Med. 2000;161(5): 1608-1613.

27. Bloomfield SA. Changes in musculoskeletal structure and function with prolonged bed rest. Med Sci Sports Exerc. 1997;29(2):197-206.

28. Roche Campo F, Drouot X, Thille AW, et al. Poor sleep quality is associated with late noninvasive ventilation failure in patients with acute hypercapnic respiratory failure. Crit Care Med. 2010;38(2):477-485.

29. Andenaes R, Kalfoss MH. Psychological distress in hospitalized patients with chronic obstructive pulmonary disease. Eur J Epidemiol. 2004;19(9):851-859.

30. Stapleton RD, Nielsen EL, Engelberg RA, Patrick DL, Curtis JR. Association of depression and life-sustaining treatment preferences in patients with COPD. Chest. 2005;127(1):328-334. 


\section{Supplementary materials Patients and methods}

\section{Evaluation criteria}

Do-not-intubate (DNI) status: decision process

According to good ethical practice and standard of care of our hospital, all patients who were admitted for acute-onchronic respiratory failure were classified as either a DNI order or not. ${ }^{1}$ This decision was made by the patient him/ herself whenever possible. When the patient does not have the capacity to make such decision, it was taken by the trusted person mandated by the patient or by a multidisciplinary team including physicians and nurses caring for the patient. Clinicians involved in the decision process included at least an intensivist and either a pulmonologist or an emergency care practitioner, who did not participate in the current study. Patients were classified as DNI when their physical disability and their underlying debilitating conditions made them poor candidates for intubation. The patient's family was informed in a clear and loyal manner, and all efforts were provided to make them understand and adhere to the medical decision. ${ }^{1}$

According to the French law 2005-370 of April 22, 2005 (Leonetti's law), ${ }^{2}$ which focuses on end-of-life decision-making, everything should be performed to respect the patient's choices. Thus, the practitioner in charge must respect the patient's wishes. ${ }^{3}$ Patients can prepare advanced directives to anticipate a critical situation where they would not be able to express their will. ${ }^{3}$ Patients can also appoint a trusted person to express their will in the case they cannot express their wishes by themselves. ${ }^{3}$ The appointment has to be made in writing. For the intensivist or the emergency care practitioner, the classical scenario is the one including a patient unable to express his/her will, for whom there are no advance directives and no previously mandated trusted person. In this particular case, which is unfortunately the most common one in clinical practice regarding patients admitted for acute respiratory failure, physicians should respect a collegial medical procedure. This last point aims at preventing the possibility of a self-fulfilling prophecy regarding the patient's prognosis. ${ }^{3}$ Our team is very keen on respecting this law at the bedside and we make everything in our power to have collegiate discussion on each case on a daily basis.

Except for invasive interventions, therapeutic management of DNI COPD patients was similar to every patient with COPD admitted for acute respiratory failure. All the patients with a DNI order were admitted to either the intensive care unit (ICU) or the step-down unit at least for the first 2 days. ${ }^{1}$ Once stabilized, they were transferred to a medical ward, where NIV could be pursued if necessary.

Table SI Clinical frailty score

\begin{tabular}{|c|c|c|}
\hline Score & Frailty grade & Description \\
\hline I & Very fit & $\begin{array}{l}\text { People who are robust, active, energetic, and motivated. These people commonly exercise regularly. They are } \\
\text { among the fittest for their age }\end{array}$ \\
\hline 2 & Well & $\begin{array}{l}\text { People who have no active disease symptoms but are less fit than those of category I. Often, they exercise or } \\
\text { are very active occasionally (that is, seasonally) }\end{array}$ \\
\hline 3 & Managing well & People whose medical problems are well controlled, but are not regularly active beyond routine walking \\
\hline 4 & Vulnerable & $\begin{array}{l}\text { While not dependent on other for daily help, symptoms often limit activities. A common complaint is being } \\
\text { slowed up, and/or being tired during the day }\end{array}$ \\
\hline 5 & Mildly frail & $\begin{array}{l}\text { These people often have more evident slowing, and need help in high-order independent activities of daily } \\
\text { living (finances, transportation, heavy housework, medications). Typically, mild frailty progressively impairs } \\
\text { shopping and walking outside alone, meal preparation, and housework }\end{array}$ \\
\hline 6 & Moderately frail & $\begin{array}{l}\text { People need help with all outside activities and with keeping house. Inside, they often have problems with stairs } \\
\text { and need help with bathing and might need minimal assistance (cuing, standby) with dressing }\end{array}$ \\
\hline 7 & Severely frail & $\begin{array}{l}\text { Completely dependent for personal care, from whatever cause (physical or cognitive). Even so, they seem } \\
\text { stable and not at high risk of dying (within } \sim 6 \text { months) }\end{array}$ \\
\hline 8 & Very severely frail & Completely dependent, approaching the end of life. Typically, they could not recover even from a minor illness. \\
\hline 9 & Terminally ill & $\begin{array}{l}\text { Approaching the end of life. This category applied to people with a life expectancy }<6 \text { months, who are not } \\
\text { otherwise evidently frail }\end{array}$ \\
\hline
\end{tabular}

Note: Adapted from McDermid RC, Stelfox HT, Bagshaw SM. Frailty in the critically ill: a novel concept. Crit Care. 20II;I5(I):30I ${ }^{4}$ 


\section{References}

1. Lemyze M, Mallat J, Barrailler S, et al. Rescue therapy by switching to total face mask after failure of face mask-delivered noninvasive ventilation in do-not-intubate patients in acute respiratory failure. Crit Care Med. 2013;41(2):481-488.

2. Loi no 2005-370 du 22 avril 2005 relative aux droits des malades et à la fin de vie. JORF no95 du 23 avril 2005 p. 7089. Code de la Santé Publique. 2005. [Law no 2005-370, April 22nd 2005, related to the patients rights and the end of life. Official Journal of the French Republic no95, April 232005 p. 7089. French Public Health Code. 2005]. Available from: https://www.legifrance.gouv.fr/affichTexte.do?cidTexte=JORFTEXT0 00000446240\&dateTexte. Accessed May 17, 2017.
3. Baumann A, Audibert G, Claudot F, Puybasset L. Ethics review: end of life legislation - the French model. Crit Care. 2009;13(1):204.

4. McDermid RC, Stelfox HT, Bagshaw SM. Frailty in the critically ill: a novel concept. Crit Care. 2011;15(1):301.

International Journal of COPD

\section{Publish your work in this journal}

The International Journal of COPD is an international, peer-reviewed journal of therapeutics and pharmacology focusing on concise rapid reporting of clinical studies and reviews in COPD. Special focus is given to the pathophysiological processes underlying the disease, intervention programs, patient focused education, and self management protocols.
Dovepress

This journal is indexed on PubMed Central, MedLine and CAS. The manuscript management system is completely online and includes a very quick and fair peer-review system, which is all easy to use. Visit $\mathrm{http}: / / \mathrm{ww}$.dovepress.com/testimonials.php to read real quotes from published authors.

Submit your manuscript here: http://www.dovepress.com/international-journal-of-chronic-obstructive-pulmonary-disease-journal 